\title{
Projeções, fantasias e relações
} sociais: uma análise junguiana sobre a pornografia na atualidade

\author{
Ana Clara Françolin TRENTO' \\ Laiany Maiara Quirino de PAULA ${ }^{2}$ \\ Mauro Sérgio da ROCHA ${ }^{2}$ \\ Rafaela Gomes LUIZ ${ }^{3}$
}

${ }^{1}$ Faculdade Pequeno Príncipe, Curitiba, PR, Brasil

2Universidade Paranaense, Umuarama, PR, Brasil

${ }^{3}$ Universidad de Araraquara, Araraquara, SP, Brasil.

Conflito de interesses:

Os autores declaram não haver nenhum interesse profissional ou pessoal que possa gerar conflito de interesses em relação a este manuscrito.

\section{Resumo}

Este trabalho teve como objetivo refletir acerca da pornografia, considerando-a um tema que, apesar de pouco debatido, mostra-se relevante para discussão no campo da psicologia. A partir de uma revisão bibliográfica, foram identificados materiais científicos que apresentam interpretações simbólicas sobre a temática, dentro da perspectiva da psicologia analítica e do método construtivo proposto por Jung. A pornografia é permeada de diferentes representações e modificou-se ao longo dos anos conforme o contexto histórico-cultural, apresentando-se como símbolo de conteúdos da psique individual e coletiva. Com base na teoria da psicologia analítica, abordou-se a relação da pornografia com o inconsciente coletivo e com os conteúdos psíquicos, associando-a aos mitos, fantasias, projeções e relações sociais. Vale destacar que o artigo tratou do tema a partir de um olhar que o relaciona aos processos clínicos, trazendo à tona a sexualidade do sujeito e sua relação com os conteúdos psíquicos, e que não se teve a intenção de propor posicionamentos morais.

\section{Descritores}

pornografia, interação interpessoal, psicoterapia analítica, projeção (mecanismo de defesa), individuação (psicologia).

Recebido: 25 mar 2021; $1^{\text {a }}$ revisão: 19 abr 2021; Aprovado: 01 jul 2021; Aprovado para publicação: 10 ago 2021 


\title{
Projections, fantasies and social relationships: Jungian analysis of pornography today
}

\begin{abstract}
The objective of this work was to reflect on pornography, considering that although there is little debate on the subject, it is relevant for discussion in the field of psychology. Through bibliographic review, identified scientific material was identified, which presents symbolic interpretations on the theme, within the perspective of analytic psychology and the constructive method proposed by Jung. Pornography is permeated with different representations and has been changing along the years according to the historical-cultural context, being regarded as a symbol of contents of the individual and collective psyche. Based on analytic psychology theory, the relationship between pornography and the collective unconscious and psychic contents was approached and connected with myths, fantasies, projections and social relationships. It is worth emphasizing that the article dealt with this theme from a viewpoint that relates it to clinical processes, bringing to light the subject's sexuality and its relationship with psychic contents, and that is not intended to propose moral positions.
\end{abstract}

\section{Descriptors}

pornography, interpersonal relationships, analytical psychotherapy, projection (defense mechanism) interpersonal interaction, individuation (psychology).

\section{Proyecciones, fantasías y relaciones sociales: un análisis junguiana sobre la pornografía en la actualidad}

\section{Resumen}

Este trabajo tuvo el objetivo de reflexionar acerca de la pornografía, considerándola un tema que, a pesar de ser poco examinado, se muestra relevante para debate en el campo de la psicología. A partir de una revisión bibliográfica, se identificaron materiales científicos que presentan interpretaciones simbólicas sobre la temática, dentro de la perspectiva de la psicología analítica y del método constructivo propuesto por Jung. la pornografía está permeada de diferentes representaciones y se modificó con el pasar de los años según el contexto histórico-cultural, presentándose como símbolo de contenidos de la psique individual y colectiva. Con base en la 
teoría de la psicología analítica, se abordó la relación de la pornografía con el inconsciente colectivo y con los contenidos psíquicos, asociándola a los mitos, fantasías, proyecciones y relaciones sociales. Vale destacar que el artículo trató del tema a partir de una mirada que lo relaciona con los procesos clínicos, trayendo a la luz la sexualidad del individuo y su relación con los contenidos psíquicos, y que no hubo intención de proponer posturas morales.

\section{Descriptores}

pornografía, relaciones interpersonales, psicoterapia analitica, proyección (mecanismo de defesa), individuación (psicología).

\section{Introdução}

Ao direcionarmos o olhar para as sociedades antigas, já vislumbramos a relação entre os sujeitos e as mais diferentes formas de se pensar o corpo. Experimentações com o próprio corpo, ou com o corpo do outro, estão presentes na história da humanidade desde os tempos mais antigos até a atualidade, vivenciadas por meio da arte, da religiosidade e de outras manifestações culturais. Essas demonstrações têm impactos também na expressão da sexualidade e na forma de se estabelecer contato com o outro. A partir dessas considerações, abordamos o tema principal deste trabalho: a pornografia. Aqui, tomada como uma das possíveis formas de o sujeito projetar sua relação com o corpo e com a sexualidade. É esse caminho que este trabalho visa transitar.

Considerando os estudos em psicologia, observou-se que, embora pouco debatida, a pornografia apresenta-se como tema bastante presente, em um universo velado, de relevância e influência no meio social. $\bigcirc$ conhecimento a respeito da pornografia pode ser erroneamente vinculado a uma visão reducionista, tornando-se comum pensá-la simplesmente como conteúdo que reproduz relações sexuais de forma vulgar. No entanto, ao contrário do que o senso comum pode levar a pensar, não podemos limitá-la apenas a esse entendimento. É necessário compreender as diferentes formas e implicações desse conteúdo na psique individual e coletiva.

Para fundamentar esta produção, compreendemos a pornografia como a encenação do obsceno (ob-sceno = fora de cena), em suas mais variadas formas de percepção. Dentro de um olhar regido pelo capitalismo, o corpo e o desejo são colocados na sociedade ocidental atual como produtos a serem consumidos. Assim, a satisfação do prazer é incentivada por uma indústria pornográfica, evidenciando o caráter socieconômico da pornografia nas produções culturais.

Considerando a relação entre capitalismo e consumo e a estruturação da psique, e em busca de um entendimento maior sobre o tema, o presente trabalho apresenta-se como possibilidade de refletir sobre a pornografia e seu entrelaçamento com os contextos relacionais. Pretendemos levar em consideração também o quanto esse tema pode caracterizar conteúdos 
projetivos, dentro de uma ótica clínica. Assim, o estudo teve como objetivo analisar a pornografia e suas possíveis representações, através de um olhar fundamentado na psicologia analítica, sem 0 intuito de realizar posicionamentos morais acerca do tema, mas lançando reflexões sobre sua relação com o meio social e a prática clínica.

Neste percurso, apresentaremos explanações de conteúdos históricos e mitológicos que contribuirão para o entendimento do tema aqui proposto. A partir de uma perspectiva analítica, foi possível compreender o quanto do processo de comunicação e sua expansão estão envolvidos com o desenvolvimento e a manutenção da pornografia.

Complementando, também pudemos identificar uma relação com figuras mitológicas, pensando aqui na dicotomia entre Dionísio e Apolo, contemplando polos opostos das vivências psíquicas. Estas forças olímpicas, veremos, entrelaçam-se com outros conteúdos psíquicos que mostram a necessidade da compreensão de aspectos negativos da anima/animus, vinculados a uma vivência em que a adição encontra sua expressão.

Por fim, com entendimento dinâmico dessas energias, buscou-se constatar o quanto uma vivência dos conteúdos psíquicos em sua totalidade contribui para que haja uma relação diferenciada com a pornografia e, consequentemente, uma relação diferenciada com a sexualidade.

Isso posto, o presente estudo propõe uma reflexão sobre a pornografia e suas implicações relacionais, visto que conteúdos contidos na pornografia podem se apresentar de forma inconsciente no âmbito social e nas transferências dentro do processo psicoterapêutico.

A metodologia empregada foi a de revisão bibliográfica, com a identificação de materiais científicos que apresentam interpretações simbólicas sobre a temática e sobre o método construtivo proposto por Jung. Considerou-se ainda Samuels (1989) e sua proposta de intercâmbio da psicologia com outros saberes.

Iniciamos a execução da atual proposta com uma explanação sobre o que entendemos como pornografia, sua relação com a comunicação/expressão e figurações atuais na sociedade.

\section{A história da pornografia}

A pornografia, como conhecemos hoje, sofreu diversas modificações desde sua origem. Suas primeiras manifestações, no Ocidente, estão ligadas principalmente ao meio artístico (literatura, escultura, música e teatro). $\mathrm{Na}$ Antiguidade Clássica, parte da pornografia da época revelava-se a partir do culto a deuses da fertilidade, aparecendo em canções de exaltação e celebração do corpo. Dessa forma, estátuas excitantes enfeitavam as construções das cidades, teatros com enredos picantes entretinham a população e vasos repletos de cenas sexuais ornamentavam a decoração das casas. Além disso, os banhos públicos e orgias eram comuns à época 
(Ceccarelli, 2011). Ainda de acordo com Ceccarelli (2011), pode-se perceber que cada civilização encontrou uma forma de vivenciar seus ímpetos sexuais, mesmo em períodos de grande repressão. Como citado, na antiguidade as civilizações experienciaram a liberdade, onde muito desse conteúdo sexual era tido como lícito.

De acordo com Gerbase (2008), durante a Idade Média esse cenário mudou. Crenças religiosas, ditadas sobretudo pela igreja católica e suas concepções de pecado, passaram a nortear o pensamento e a maneira de se relacionar com o corpo. Após períodos de certa vivência dos desejos e prazeres carnais, esses mesmos conteúdos eram então entendidos como pecados "da carne", acompanhados da noção de culpa.

Nesse contexto, surgiu a palavra pornografia, da junção das palavras "pornô" - relacionada à prostituição e à depravação - e "grafia" significando a escrita. $O$ termo passou a ser usado para designar os escritos que tratavam da prostituição manifestada na literatura durante o lluminismo (Ceccarelli, 2011).

Com o decorrer dos séculos, a evolução tecnológica trouxe à pornografia outras formas de exposição e ela começou a ser veiculada em revistas, imagens, vídeos, filmes e sites, que compõem o que pode ser chamado de indústria pornográfica. Houve então a comercialização do prazer, em que o fora de cena, embora ainda privado e estigmatizado, tornou-se facilmente acessível (Oliveira, 2015).

Nos dias atuais, a concepção do significado de pornografia sofreu também alterações, não havendo mais a vinculação exclusiva da mesma com a prostituição, mas sim, com a encenação do obsceno, ou seja, daquilo que está fora de cena: o íntimo se tornando exposto (Oliveira, 2015). Nessa perspectiva, é importante ressaltar que a pornografia, por si mesma, não é algo mau ou bom. É a partir de suas funções social e pessoal que ela passou a receber um julgamento que, "[...] só pode ser entendido dentro do sistema de valores da cultura onde ela se manifesta" (Ceccarelli, 2011, p. 9).

Em vista dos pontos apresentados, entende-se que a forma de o ser humano relacionar-se com a pornografia é distinta em cada período histórico e em cada sociedade, tendo em vista a valorização ou não do corpo em seus variados aspectos.

\section{Apolo e Dionísio: polos opostos na relação com a pornografia}

Como exposto, as diferentes visões sobre o fora de cena, nas quais a vivência dos desejos se estabelece em maior ou menor intensidade energética, alternaram-se simultaneamente com os contextos históricos. Ao analisar essas narrativas da história humana, é possível compreender a relação do sujeito com a sociedade e suas possibilidades de transformação. 
Encontra-se, nesse contexto, a contribuição da mitologia para exemplificar as diferentes realidades das narrativas de um povo e como estas narrativas relacionam-se com os mais variados conteúdos da psique. As histórias míticas narram eventos como a criação do mundo, as origens do homem, dos animais e plantas e tantos outros fenômenos que contribuíram para a transformação humana dos tempos primórdios à atualidade (Eliade, 2013). Em específico, destacamos aqui, as experimentações do outro e do próprio corpo.

É fato que, com o passar do tempo, as narrativas mitológicas perderam força, sendo desvalorizadas em comparação às explicações objetivas e racionais. No entanto, é inegável seu valor atual para a compreensão da psique humana dentro da psicologia analítica e para o assunto abordado neste estudo. Assim, compreende-se os mitos como exemplos das situações vividas, considerando que os arquétipos materializam-se através deles, oferecendo a base para a construção dos temas mitológicos (Savaris, 2007).

De forma mais específica, para compor este estudo, abordamos dois deuses da mitologia grega, a saber, Apolo e Dionísio, que causaram impactos na vivência humana e contribuíram para uma relação distinta das ideias sobre pornografia, destacando-se que a forma de uma cultura lidar com a sexualidade é também influenciada pela forma como a sexualidade é argumentada nos mitos (Ceccarelli, 2007).

Nesse sentido, a compreensão de determinados conteúdos mitológicos pode contribuir para o entendimento de como a pornografia é vista atualmente. Logo, Apolo e Dionísio representam polos opostos da vivência psíquica, cuja base arquetípica e simbólica é de extrema importância para a compreensão analítica do tema proposto. Dessa forma, segue uma explanação sobre essas diferentes forças do Olimpo e de sua relação com a pornografia.

Comecemos nosso percurso mitológico por Dionísio, filho de Zeus e Sêmele. De Dionísio vem o caráter das explosões dos instintos e dos excessos. Ele é considerado o deus dos vinhos, das festas, das mulheres e da tragédia e, assim, a natureza dionisíaca representa os estados alterados da consciência, tendo profundas ligações com a morte (Brandão, 1987). Em termos psicológicos, se o indivíduo não entra em contato com essas energias, elas permanecem na psique como emoções selvagens, incapazes de se vincularem à realidade do corpo. Segundo a índole dionisíaca, a experiência com o corpo proporciona relações íntimas com os próprios sentimentos - o corpo que fala, pulsa, afeta, transborda e sente, proporcionando ao sujeito vivências libertadoras ou aprisionadoras (López-Pedraza, 2002).

A experiência dionisíaca tem viés duplo e simultâneo de subordinação e de autonomia. Como exemplo de aprisionamento, "o dependente, [...] vive a experiência como uma possessão; sem reconhecer Dionísio, tenta submetêlo ou aprisioná-lo, sem sucesso" (Fortim \& Araújo, 2013, p. 4). Porém, de forma estruturante, Dionísio pode ser visto como liberdade e oportunidade para a criatividade e a expansão da atividade consciente (Palomo, 2006). 
Contrapõe-se a essas energias, o filho de Zeus e Leto, o deus Apolo. Portador da luz, harmonia e equilíbrio, caracterizado mitologicamente também como deus solar, deus da música e da poesia, sendo o primeiro porta-voz de seu pai, Zeus (Brandão, 1987). Digno de perfeição, a natureza apolínea representa a conquista da consciência solar, na qual o ego é considerado centro (Ribeiro, 2012).

Apolo e Dionísio representam conceitos opostos e complementares, e da sua integração tem-se o processo de individuação, um movimento para o desenvolvimento de potencialidades do sujeito, para o surgimento de novos modos de vida. A experiência de vivenciar a loucura dionisíaca atrelada à harmonia de Apolo funde o princípio da reciprocidade, compreendido como meio de evitar a unilateralidade e de permitir o conhecimento da polaridade inconsciente, seja ela de caráter apolíneo, seja de caráter dionisíaco, inserindo-a dentro das relações conscientes (Ribeiro, 2012). Para tanto, a tensão desenvolvida entre os opostos, isto é, o fluxo enérgico ocorrido na transformação do conteúdo, possibilita a função transcendente (Penna, 2013), também conhecida como símbolo unificador. Assim, a função transcendente reconcilia os opostos, consciente e inconsciente, mediante traduções acessíveis ao entendimento, ampliando a consciência e atuando de forma dinâmica.

Apesar da constante transformação relacionada aos conceitos de pornografia e sexualidade nos últimos anos, a pornografia continua sendo por vezes um tabu, visto que a ligação com a energia mitológica de Dionísio, que estabelece uma relação com o corpo e os desejos, muitas vezes não é reconhecida. Ainda não se discute de forma aberta a seu respeito; mesmo que visível e presente, não se fala sobre o assunto. Dessa forma, nota-se uma vivência unilateral, na qual forças apolíneas são priorizadas em detrimento dos impulsos dionisíacos, gerando uma vivência onde o desejo, em sua forma natural, é abafado.

\section{A vivência inconsciente dos desejos}

O sujeito, ao reprimir suas próprias vontades dionisíacas e fantasias pornográficas, não as vivencia conscientemente, mas de maneiras desconhecidas, por exemplo, através das projeções. Segundo Jacoby (2011), falamos de projeção quando conteúdos intrapsíquicos do sujeito são vivenciados no mundo externo de forma inconsciente. Esse mecanismo psíquico ocorre quando um aspecto desconhecido da nossa personalidade é ativado, fazendo com que o sujeito o veja em outra pessoa, sem a consciência de que este conteúdo pertence a si mesmo (Sanford, 1987).

É necessário que haja uma compreensão do que pertence ao sujeito e do que pertence ao outro, para que o outro não se torne apenas um objeto de necessidades e fantasias inconscientes. Ao se pensar na relação com a pornografia, o sujeito se satisfaz a partir de suas fantasias, desprendendo-se de uma relação real com o objeto. $O$ outro torna-se somente uma peça da 
engrenagem para alcançar o fim desejado: o prazer. Esse outro será reduzido ao papel inconsciente que o sujeito deu a ele, reduzido a um objeto de posse. Por outro lado, quando há reconhecimento e integração das energias dionisíacas e apolíneas, o próprio sujeito pode ser capaz de compreender a representação de conteúdos pornográficos para si (Jacoby, 2011).

Essa redução inconsciente do outro - de alguém com quem me relaciono para um objeto de minha posse - pode acontecer caso o sujeito não esteja consciente dos seus próprios conteúdos e daquilo que o leva a buscar a realização de suas fantasias pela pornografia. Na busca desta realização, intensifica-se uma relação superficial com o outro, que se torna um corpo a ser consumido. Com isso, busca-se com que o outro supra necessidades de prazer imediato, o que evidencia a necessidade de uma estruturação psíquica que visa à integralidade e a um maior esclarecimento de suas projeções.

Em prol dessa possibilidade consciente de se relacionar com conteúdos pornográficos, temos as implicações de conteúdos arquetípicos que estão relacionadas às expressões masculinas e femininas inconscientes. Falamos aqui da figuração anima/animus, relevante para nossas discussões. Esses conteúdos podem ser representantes da sedução, da sensibilidade e do encantamento, além de contribuições intuitivas e receptivas, ao conduzirem a conteúdos inconscientes. Enquanto estabelecerem relações positivas com o ego, podem servir como um guia espiritual para o processo de individuação. Todavia, uma vez conectados aos seus aspectos negativos, essas estruturas psíquicas, quando não desenvolvidas, mantêm-se infantilizadas (Jung, 1964/2016). Nesse sentido, podem levar o sujeito a utilizar a pornografia de forma compulsiva como meio de alimentar suas vontades eróticas. Neste aspecto, podemos compreender a pornografia também como possibilidade de vivenciar fantasias e desejos conscientes e inconscientes (Ceccarelli, $2011)$.

Em virtude disso, percebe-se que as relações são influenciadas por conteúdos inconscientes que afetam a forma do sujeito interagir consigo e com o outro. Assim, percebe-se que, quando esse conteúdo inconsciente é experienciado apenas na realidade externa, o sujeito pode se tornar vítima e dependente de suas próprias fantasias (Jung, 1964/2016). Aqui, em específico, das fantasias vinculadas à pornografia.

É importante que o sujeito aprenda a reconhecer e a se relacionar com os próprios conteúdos, integrar partes conscientes e inconscientes, a fim de considerar sua individualidade, desejos e vontades (Jacoby, 2011). Ter consciência das imagens projetadas e entrar em contato com os próprios conteúdos psíquicos é relevante para o autoconhecimento e para a transformação da relação com a pornografia e com os outros.

O entendimento desse processo pode proporcionar uma elaboração, auxiliando na redescoberta da totalidade (López-Pedraza, 2002), além de uma relação mais consciente com conteúdos pornográficos, visto que 
lidamos com conteúdos não encenados do nosso cotidiano. Também possibilita a compreensão das partes não reconhecidas da dualidade colocada por Dionísio e Apolo, estabelecendo uma forma diferenciada de se lidar com essas energias, individual e coletivamente.

\section{A coletividade na produção do ideal}

Considerando a coletividade/indivíduo e o conceito de inconsciente coletivo proposto por Jung (1964/2016), um ponto relevante a ser pensado é como a pornografia permeia as relações sociais e culturais do indivíduo, estabelecendo ideias e padrões adotados muitas vezes de forma inconsciente. Segundo Barros (2005), tais padrões agem como ferramentas para a construção e desconstrução do próprio ser, permeados pela busca da imagem desejável e sendo refletidos na relação com o outro, o que pode gerar expectativas dificilmente supridas. Falamos aqui da vivência através das imagens e fantasias e não do real apresentado. Assim, com relação à vida amorosa e à vida sexual, assistimos, de um lado, uma incitação constante à sexualidade e, ao mesmo tempo, a veiculação de modelos rígidos que ditam modos de ser e agir.

É nesse sentido que,

As informações que obtemos sobre os diversos aspectos que formam o mundo - por exemplo, as novas tecnologias, a mídia e seu ávido poder consumista - são apreendidas por nós como uma parte de nosso corpo unindo-se com nossa imagem corporal, transformando-nos em camaleões que se adaptam àquilo que as circunstâncias exigem (Barros, 2005, p. 552).

Dessa maneira, é inegável a influência dos meios de comunicação e da indústria do consumo sobre o incentivo a padrões idealizados, gerando inalcançáveis expectativas quando relacionadas ao real (Ribeiro \& Zorzetto, 2004). Assim, nos encontramos como atores em um palco constituído por imagens preestabelecidas, nas quais os sujeitos colocam-se em situações que não correspondem à personalidade de si mesmos. Nesse sentido, a pornografia aparece, como citado, nos movimentos "en-cenados", naqueles em que o sujeito não se percebe. É nesse processo que ele apenas satisfaz o desejo e não à totalidade de si.

Considerando o processo de individuação e sua relação com a coletividade, cabe ao sujeito o reconhecimento de si, em meio às tantas imagens que entrelaçam o campo inter-relacional. É a partir disso que o sujeito pode, então, diferenciar-se do coletivo e buscar sua própria existência, tomando consciência das projeções (Barros, 2005). Nesse contexto, a análise simbólica desses conteúdos pode colaborar para que o sujeito perceba-se nesse emaranhado de situações, ideais e reais, conscientes e inconscientes, objetivando uma conexão entre seu corpo e a relação com a própria sexualidade. 


\section{O processo de individuação e a relação terapêutica}

A partir do exposto, entende-se o quanto a reflexão sobre o tema aqui proposto possui relevância para a prática clínica. $\bigcirc$ mesmo se mostra possuidor de conteúdos básicos da psique, relacionados às possíveis projeções de conteúdos eróticos e relacionais. Dizemos isso, pois verificamos a influência de tais conteúdos em uma vivência na qual se realizam apenas fantasias sexuais, quando se pensa em pornografia. Assim, o estar fora de cena representa uma vivência unilateral do processo de satisfação do sujeito e, quando ele se relaciona com material pornográfico, visa apenas à satisfação de uma parte do conteúdo envolvido. Pode-se dizer que, nessa perspectiva, Apolo e Dionísio estão separados e, ao mesmo tempo, buscando a satisfação naquele momento (López-Pedraza, 2002).

Dentro desse processo e considerando essa busca pela satisfação dos desejos, podemos pensar no par anima/animus, quando suas formas não vivenciadas e projetadas adquirem uma relação com a fantasia de maneira inconsciente, não contribuindo para a estruturação psíquica. Na satisfação do prazer, tem-se a busca pelo par e pela realização do desejo em sua forma mais idealizada, a exemplo de Narciso que se satisfaz consigo mesmo. Com isso, o sujeito busca vivenciar a imagem do par sexual perfeito, mais uma vez unilateralmente, o que o leva à compulsão. Nessa perspectiva e tendo em vista que, geralmente, a compulsão pela pornografia e a vivência unilateral dos conteúdos ocorrem devido à falta de consciência acerca dos conteúdos inconscientes presentes na vida, ressalta-se a possibilidade e a importância da busca do indivíduo pelo autoconhecimento e pela transformação de sua relação com seus conteúdos conscientes e inconscientes. Esta busca é citada por Edinger (2004) como o processo de individuação, quando o sujeito busca também a si, por meio da relação com o desejo, e toma consciência de suas projeções. Uma oportunidade de transcender pela integração das partes consciente e inconsciente.

Ainda segundo Edinger (2004), a individuação é o processo de desenvolvimento da totalidade psíquica que implica lidar com aspectos obscuros da personalidade e com mudanças, a fim de reorientar e reorganizar a vida psíquica. Não sendo exclusiva do processo psicoterapêutico, a individuação é uma transformação contínua que assimila os conteúdos antes vivenciados de forma inconsciente. Assim, o sujeito transforma sua própria realidade e aumenta seu poder de escolha frente às experiências vividas, ressignificando sua relação com si mesmo e com o outro. Liga-se essa perspectiva ao tema, uma vez que a pornografia pode indicar ao sujeito duas rotas: uma na qual é vivenciada de forma consciente e outra em que se concretiza pela adição ou pela idealização de um par sexual que corresponda aos desejos de seu inconsciente. Neste segundo caso, quando as fantasias sexuais sucumbem à compulsão, é que a psicologia mostra-se essencial para a compreensão simbólica dos conteúdos, com a possibilidade de, mesmo com dificuldade, elevar o 
conteúdo à consciência (Sanford, 1987). Dessa forma, o processo psicoterápico será um meio pelo qual o indivíduo poderá buscar a individuação.

Tendo em vista então a psicologia e o setting analítico, precisamos ressaltar que as projeções também podem ser encontradas no âmbito do setting terapêutico, onde recebem o nome de transferência e contratransferência. Para compreendê-las, é necessário identificar a relação que se estabelece entre analista e analisando dentro do processo terapêutico. Segundo Jung (1954/2013), a psicoterapia pode ser definida como um processo dialético, partindo do princípio de que cada pessoa é um sistema psíquico que, ao se relacionar com outro sistema psíquico, age sobre o outro, estabelecendo uma relação de troca. Dessa forma, "tanto o analista como o analisando têm suas fantasias sobre o outro, cada um está sempre a circunscrever o outro em sua imaginação" (Guggenbühl-Craig, 2004, p. 51). Essa condição deve ser analisada, visto que assim como a união do par anima/animus está relacionada à busca pela totalidade, "o fenômeno da atração erótica e sensual intensa na psicoterapia deveria também ser compreendido como símbolo dessa unificação" (Guggenbühl-Craig, 2004, p. 64-65).

Importante visualizar que a sexualidade deve ser observada de forma mais ampla, compreendida não apenas como símbolo de algo sexual, mas como união dos opostos. Assim, torna-se necessário que o profissional perceba quais fantasias eróticas permeiam a relação terapêutica para que o processo não se torne uma união constituída por projeções não esclarecidas (Guggenbühl-Craig, 2004). Esses aspectos, dentro do contexto clínico, fazem com que o profissional traga à consciência conteúdos relacionados com a sexualidade do sujeito e, se for o caso, compreenda de forma simbólica conteúdos pornográficos que permeiam as relações sociais. Segundo Jung (2013), o esclarecimento das projeções entre analista e analisando contribui também para que o processo caminhe rumo à individuação.

Através do processo de individuação, é possível que o sujeito transforme sua relação com seus conteúdos e com a pornografia, ressignificando o que antes estava fora de cena e integrando em si novas representações. Devemos aqui nos lembrar mais uma vez que, diante da perspectiva teórica apresentada, não se faz necessário posicionamentos morais acerca da pornografia e das fantasias sexuais. Segundo Ribeiro (2012), entende-se que estes são conteúdos do indivíduo que, quando desconhecidos, afetam-no diretamente em suas relações e concepções sobre o mundo a sua volta. É importante considerar também que estes conteúdos, após esclarecidos, podem ser integrados e, dessa forma, ajudar o indivíduo em sua busca pela totalidade e pela consciência de si, uma vez que a transformação torna-se uma possibilidade (Fortim \& Araújo, 2013).

A pornografia então, que é normalmente vista apenas como objeto de desejo e como algo fora de cena, torna-se uma possível aliada no acesso ao inconsciente do indivíduo, auxiliando na ressignificação de conteúdos. É assim que, de maneira diversa da unilateralidade observada na vivência 
somente de Apolo ou de Dionísio, o sujeito aceita-se como integral e consciente de suas potencialidades, capaz de construir novos rumos e de estabelecer uma relação diferenciada com a pornografia, com a sua própria sexualidade e com o outro (Ribeiro, 2012).

\section{Considerações finais}

A partir dos estudos pesquisados e da observação dos conteúdos apresentados, foi possível chegarmos ao objetivo proposto: refletir e compreender a pornografia por meio de suas representações simbólicas. Partimos da prerrogativa de que a pornografia faz-se visível pela encenação do obsceno, rejeita regras, posicionamentos morais e apresenta os bastidores do desejo. O atual cenário da indústria pornográfica vende o gozo, seguindo rastros deixados durante a história da humanidade pela pintura, escultura, literatura, religiosidade e demais formas de expressões humanas.

Acrescente-se que as representações da pornografia, pela perspectiva da psicologia analítica, movimentam conteúdos que podem influenciar o sujeito, de modo a produzir fantasias eróticas que podem ser vivenciadas por ele de maneira negativa ou de maneira positiva. Isso posto, a vivência negativa da pornografia acontece de forma unilateral, com a polarização apenas de Dionísio ou de Apolo, na qual o sujeito apenas vivencia seus próprios desejos e projeções inconscientes, podendo tornar-se um sujeito adicto. Consequentemente, as energias dionisíacas e apolíneas, enquanto forças criativas, precisam ser integradas a fim de proporcionar o equilíbrio psíquico. Desse modo, a relação inconsciente com o conteúdo pornográfico, refletida através das projeções, dificulta o estabelecimento de uma relação com o par anima/animus e não contribui com o processo de individuação.

No contexto clínico, a compreensão acerca dos conteúdos pornográficos apresentados no processo psicoterápico - como as fantasias eróticas que emergem através da transferência e contratransferência - torna possível um maior entendimento simbólico das representações contidas nas relações e na sexualidade dos sujeitos.

A temática explanada no decorrer desta pesquisa possibilita também perceber a forma como o sujeito estabelece contato com a pornografia e com as fantasias em suas relações, para assim identificar projeções e associações que emergem no contexto clínico, com a possibilidade de transformar essa vivência.

\section{Referências}

Barros, D. D. (2005). Imagem corporal: a descoberta de si mesmo. História Ciência, Saúde Manguinhos, 12(2), 547-554. https://doi.org/10.1590/S0104-59702005000200020. 
Brandão, J. D. S. (1987). Mitologia grega (Vol. II). Petrópolis, RJ: Vozes.

Ceccarelli, P. R. (2007). Mitologia e processos identificatórios. Tempo Psicanalítico, 39(1), 179-193.

Ceccarelli, P. R. (2011). A pornografia e o ocidente. Revista (In) visível, 1, 25 34.

Edinger, E. F. (2004). Ciência da alma: uma perspectiva junguiana. São Paulo: Paulus.

Eliade, M. (2013). Mito e realidade (P. Civelli, trad.). São Paulo: Perspectiva. (Trabalho original publicado em 1963).

Fortim, I., \& Araújo, C. A. D. (2013). Psicologia analítica e as dependências: uma revisão. Revista Junguiana, 31 (2), 12-22.

Gerbase, C. (2008). O corpo feminino no cinema: entre a fascinação vital e o pecado mortal. Comunicação e Informação, 11 (2), 181 - 191.

Guggenbühl-Craig, A. (2004). O abuso do poder na psicoterapia e na medicina, serviço social, sacerdócio e magistério. São Paulo: Paulus.

Jacoby, M. (2011). O encontro analítico: transferência e relacionamento humano. Petrópolis, RJ: Vozes.

Jung, C. G. (2013). Princípios básicos da prática da psicoterapia. In A prática da psicoterapia (16a ed., OC. Vol. XVI/1, pp. 13-31). Petrópolis, RJ: Vozes. (Trabalho original publicado em 1954).

Jung, C. G. (2016). O homem e seus símbolos. Rio de Janeiro: HarperCollins Brasil. (Trabalho original publicado em 1964).

Oliveira, L. D. B. (2015). Imagens fantasmas e o imaginário da putaria: aproximação a um pensamento feminino para a estética e a comunicação. Dissertação de Mestrado), Faculdade de Comunicação, Universidade de Brasília, Brasília, DF.

Palomo, V. (2006). Uma contribuição da psicologia analítica para a compreensão das farmacodependências. In D. X. Silveira, \& F. G. Moreira (Eds.), Panorama atual de drogas e dependências (Vol. 1, pp. 234-239). São Paulo: Atheneu.

López-Pedraza, R. (2002). Dioniso no exílio: sobre a repressão da emoção e do corpo. São Paulo: Paulus.

Penna, E. M. D. (2013). Epistemologia e método na obra de C. G. Jung. São Paulo: Educ.

Ribeiro, M., \& Zorzetto, R. (2004). O avesso de Narciso. Pesquisa Fapesp, (103): 34, 34, 37, 39.

Ribeiro, M. (2012). Drogas: uma leitura junguiana da história e da clínica das dependências. Monografia, Sociedade Brasileira de Psicologia Analítica de 
São Paulo, São Paulo. Recuperado em 04 de maio de 2019, de http://sbpa.org.br/portal/wpcontent/uploads/2013/02/Drogas.pdf

Samuels, A. (1989). Escolas da Psicologia Analítica. In Jung e os pósjunguianos (pp. 10-20). Rio de Janeiro: Imago.

Sanford, J. A. (1987). Os parceiros invisíveis: o masculino e o feminino dentro de cada um de nós. São Paulo: Paulus. (Trabalho original publicado em 1987).

Savaris, L. E. (2007). Mitos e arquétipos. Symbolon, Estudos Junguianos.

Recuperado em 2 julho de 2019, de

http://www.symbolon.com.br/artigos/mitosearquetip.htm

Minicurrículos: Ana Clara Françolin Trento - Pós-Graduanda em

Psicologia Hospitalar e da Saúde pela Faculdade Pequeno Príncipe;

graduada em Psicologia pela Universidade Paranaense

Laiany Maiara Quirino de Paula - graduada em Psicologia pela Universidade Paranaense.E-mail: I.paula@edu.unipar.br

Mauro Sérgio da Rocha - docente do Curso de Psicologia da Universidade

Paranaense.

Rafaela Gomes Luiz - pós-graduanda em Psicologia, Nutrição de Transtornos Alimentares pela Universidade de Araraquara; graduada em Psicologia pela Universidade Paranaense. 